\title{
Cyclosporin neurotoxicity in cardiac transplant recipients
}

\author{
RUSSELL J M LANE, * SHANE W ROCHE,* ANTHONY A W LEUNG, $\dagger$ \\ ALINA GRECO, $\dagger$ LEO S LANGE*
}

From the Regional Neurosciences Centre, Charing Cross Hospital, ${ }^{*}$ London and the Mount Vernon Scanner Centre, Mount Vernon Hospital, $\uparrow$ Northwood, Middlesex, UK

SUMMARY Cyclosporin toxicity may produce a wide range of neurological disorders. We report three patients whose neurological problems developed while taking cyclosporin following cardiac transplantation, but resolved rapidly when the drug was discontinued. In two cases, MRI revealed abnormalities which disappeared with clinical recovery. Blood cyclosporin concentrations were not markedly increased, and it is possible that the neurotoxic effects of cyclosporin are mediated by metabolites, through an effect on the blood-brain barrier.

A number of reports have implicated cyclosporin in the pathogenesis of neurological disorders which may develop following bone marrow and organ transplantation. ${ }^{1}$ These observations suggest that the drug might be neurotoxic but most of the patients in these reports had also received other potentially neurotoxic drugs, and coincidental metabolic factors may have contributed to the clinical picture. We report three patients who developed neurological dysfunction whilst taking cyclosporin following cardiac transplantation, in the absence of such additional metabolic complications. Magnetic resonance imaging (MRI) changes in two cases support the suggestion that cyclosporin might exert its neurotoxic effect by damaging the blood brain barrier. ${ }^{2}$

\section{Case 1}

In July 1986, a 17 year old boy was admitted with a 5 day history of a single grand mal seizure, confusion, change in behaviour characterised by aggression, paranoia and agitation, and general malaise with intermittent pyrexia. He had undergone cardiac transplantation 26 days earlier because of cardiomyopathy following adriamycin treatment for histiocytosis-X. On admission he was taking cyclosporin 370 $\mathrm{mg}$ bd together with dipyridamole, cimetidine, frusemide,

Address for reprint requests: $\operatorname{Dr} \mathbf{R} \mathbf{J}$ M Lane, Charing Cross Hospital, Fulham Palace Road, London W6 8RF, UK.

Received 2 October 1987 and in final revised form 1 July 1988. Accepted 1 July 1988 and azathioprine. His temperature was $39^{\circ} \mathrm{C}$ and he was confused and amnestic. Although he complained of tingling in his hands and weakness and dragging of his left leg, no other definite neurological abnormalities were found. Routine blood and serological tests and measurements of serum $\mathrm{Mg}^{++}$were normal, and there was no evidence of infection. EEG, CT brain scan and CSF examinations were unremarkable. Whole blood cyclosporin level was $438 \mathrm{ng} / \mathrm{ml}$ (therapeutic range $100-400 \mathrm{ng} / \mathrm{ml}$ ). He improved somewhat over the next few days but remained slightly confused and was eventually readmitted on 11 September 1986 with an acute recurrence of his original symptoms, together with a severe postural tremor and a mild left hemiparesis. This progressed over the next 24 hours to generalised myoclonus and ultimately status epilepticus and coma. CT, serological and CSF examinations were again unremarkable and no pathogens could be identified. Although the blood cyclosporin level was acceptable at $462 \mathrm{ng} / \mathrm{ml}$, the drug was withdrawn and within 12 hours he made a dramatic recovery, with eventual resolution of his confusional state and myoclonus. Two MRI studies were performed. The first, 2 days after the initial admission, showed a focal area of increased signal density, without mass effect, in the medial surface of the temporal lobe on the right, and a similar abnormal signal in the right cerebellar hemisphere (fig la and b). One week after stopping the cyclosporin these abnormal signals had diminished significantly. Six months later, he remains well despite being on a small maintenance dose of cyclosporin because of recurrent rejection.

Case 2

In January 1987, a 52 year old retired engineer was referred 

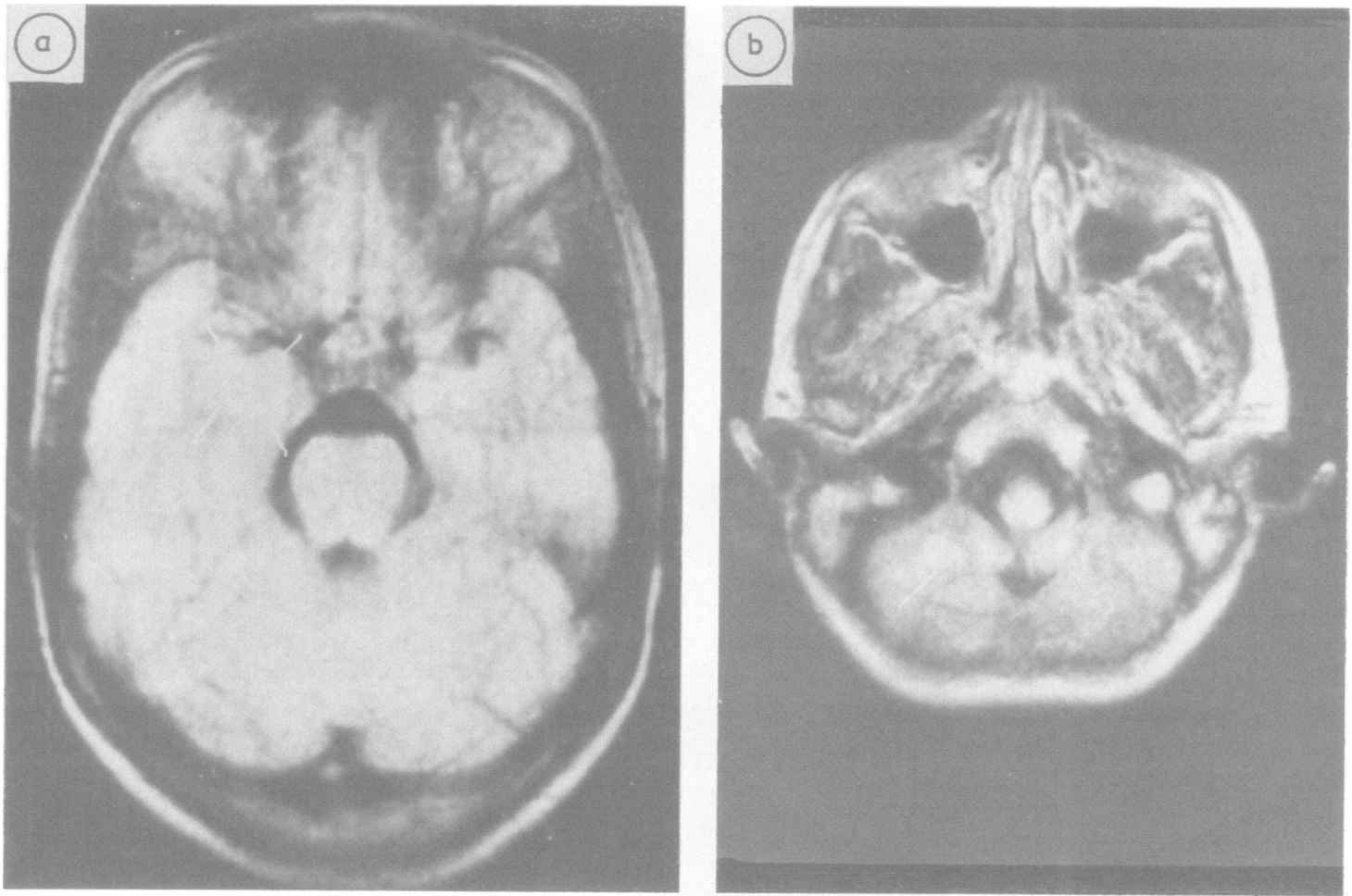

Fig 1 Case 1 MRI showing areas of increased signal density in the right hippocampal area (a) and right cerebellar hemisphere (b).

with a 3 week history of low back pain extending into the hips and upper legs, together with progressive weakness of the legs, walking difficulty and vague distal numbness. He denied symptoms in the arms or disturbance of sphincter function. He had undergone cardiac transplantation in May 1980 for progressive ischaemic cardiomyopathy and had remained stable on maintenance steroids and azathioprine until May 1985 when cyclosporin had been introduced for chronic rejection. Neurological examination showed abnormalities only in the lower limbs. The legs were globally weak and the tone was reduced, with depressed knee jerks and absent ankle jerks. Sensation to all modalities was reduced to the anterior superior iliac spines and Romberg's sign was positive. Plantar responses were absent. Myelography was normal and the CSF unremarkable (protein $0.41 \mathrm{~g} / \mathrm{l}$ ). EMG and nerve conduction studies were normal although the recruitment pattern was grouped, suggesting an upper motor neuron lesion. Serum creatine kinase level was normal. The onset of the leg symptoms corresponded to a doubling of the cyclosporin dose from 170 to $240 \mathrm{mg}$ daily. The whole blood cyclosporin level on 24 November 1986 had been $60 \mathrm{ng} / \mathrm{ml}$ and this had risen to $385 \mathrm{ng} / \mathrm{ml}$ by January 1987 and to 490 $\mathrm{ng} / \mathrm{ml}($ CSF $19 \mathrm{ng} / \mathrm{ml})$ by the time of admission. The cyclosporin was withdrawn and over the next 6 months the patient made a complete recovery.

Case 3

A 24 year old Icelandic man had undergone heart-lung trans- plantation in February 1988 because of congenital heart disease. Five weeks post-operatively he developed progressive malaise, headache and neck stiffness and was admitted to Harefield hospital, where he suffered a series of generalised seizures, some preceded by focal jactitation on either the right or left side. Lumbar puncture showed a CSF protein of $0.88 \mathrm{~g} / 1$ but was otherwise normal. The following day he became increasingly drowsy and suffered two further seizures. On transfer to our unit he was stuporose, and agitated when aroused. His oral temperature was $37.5^{\circ} \mathrm{C}$ and he exhibited severe meningism. There were no focal neurological signs, although he had symmetrical hyper-reflexia. CT showed no abnormality, but he was found to be hypomagnesaemic (0.65 mM, normal range 0.7-1.0 mM). Cyclosporin was discontinued and a loading dose of phenytoin administered intravenously, together with magnesium supplements. He had no further seizures and the following day was much improved, although the meningism persisted, and he complained of blurred vision. A further lumbar puncture showed a CSF protein of $0.86 \mathrm{~g} / 1$ but no cells. The meningism and hyper-reflexia resolved over the next 12 hours. Despite the magnesium supplements, his serum $\mathrm{Mg}^{++}$remained low $(0.66 \mathrm{mM})$ after recovery. The whole blood cyclosporin level in February had been $56 \mathrm{ng} / \mathrm{ml}$, but was found to be in the toxic range at $669 \mathrm{ng} / \mathrm{ml}$ on admission, although the dose of drug taken had not been changed over this period. MRI two days after admission showed an unusual bright density in the left corona radiata and some 

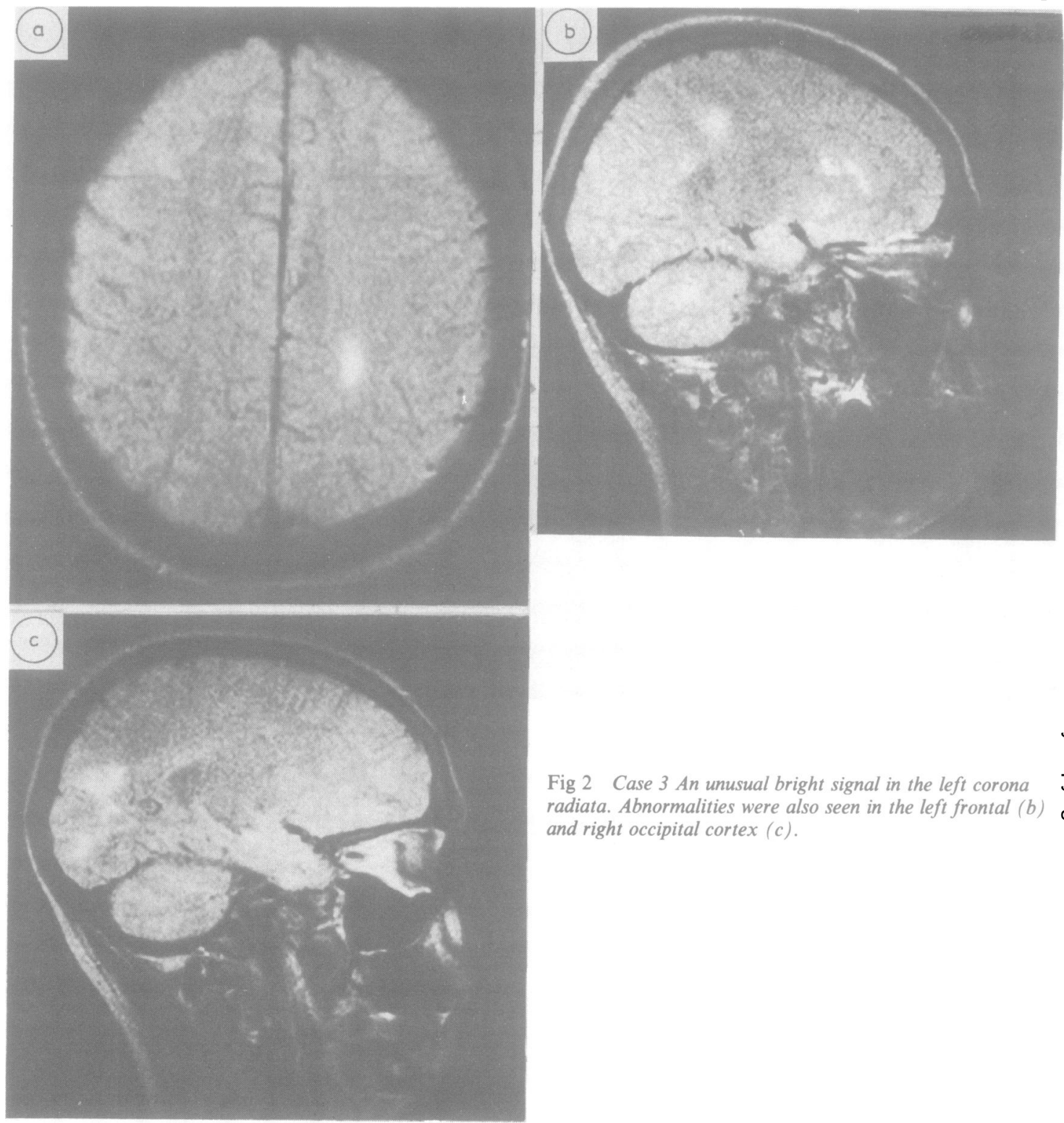

Fig 2 Case 3 An unusual bright signal in the left corona radiata. Abnormalities were also seen in the left frontal $(b)$ and right occipital cortex $(c)$.

less prominent abnormal signals in the right occipital and left frontal cortex (fig $2 a, b$ and $c$ ). A second study one month after recovery showed complete resolution of these lesions.

\section{Discussion}

Seizures associated with cyclosporin treatment were first described in bone marrow transplant recipients, and subsequently in renal and liver transplant patients. ${ }^{1}$ Other neurological disorders have since been reported in patients on this drug, including coma and encephalopathy, cortical blindness, tremor, 'ataxia, hemi-, tetra- and paraparesis, and features of peripheral neuropathy. ${ }^{13}$ In many cases, additional factors such as renal and hepatic insufficiency, hypertension, electrolyte imbalance, concomitant administration of other potentially neurotoxic drugs, or intravenous methyl prednisolone, and features of impending rejection, have cast doubts concerning the role of cyclosporin in the pathogenesis of these neurological complications. ${ }^{4}$ Withdrawal or reduction in dose of the drug has generally resulted in resolution of 
signs and symptoms, but cases of fatal convulsions and coma have been reported. Pathological studies in such cases have revealed cerebral oedema ${ }^{5}$ and evidence of disruption of the blood-brain barrier, ${ }^{2}$ attributed to microvascular damage induced by the drug through toxic effects on vascular basement membranes. ${ }^{2}$ This concept would be supported by the MRI changes in our patients and by previous reports of low-density lesions in the white matter on computed tomography. ${ }^{67}$

Most cases of cyclosporin neurotoxicity have occurred with high doses and drug levels above the accepted therapeutic range, but there is no general correlation between blood levels and toxic effects in other systems in cardiac transplant patients. ${ }^{8}$ Levels in two of our patients were within or only slightly above the accepted therapeutic range, and it is possible that the neurotoxic effects are in fact mediated by metabolites of cyclosporin, which can be detected in blood by high performance liquid chromatography. ${ }^{10}$ A close association between neurotoxic effects and hypomagnesaemia, possibly caused by the nephrotoxic action of the drug, was noted in one series of bone marrow transplant recipients ${ }^{9}$ and could have been an aggravating factor in our third patient, although our patient recovered despite persistently low serum $\mathrm{Mg}^{++}$levels.

We thank Professor Magdi Yacoub for permission to report the case histories of patients under his care.
References

1 Rubin AM, Kang, H. Cerebral blindness and encephalopathy with cyclosporin A toxicity. Neurology 1987;37:1072-6.

2 Sloane JP, Lwin KY, Gore ME, Powles RL, Smith JF. Disturbance of blood-brain barrier after bone-marrow transplantation. Lancet 1985;ii:280-1.

3 Atkinson K, Biggs J, Darveniza P, Boland J, Concannon A, Dodds A. Cyclosporine-associated central-nervous-system toxicity after allogenic bonemarrow transplantation. $N$ Engl J Med 1984;310:527.

4 Gross MLP, Pearson RM, Sweny P, Moorhead JF. Convulsions associated with cyclosporin $\mathrm{A}$ in renal transplant recipients. Br Med J 1985;290:555.

5 Velu T, Debusscher L, Stryckmans PA. Cyclosporinassociated fatal convulsions. Lancet 1985;i:219.

6 Shah D, Rylance PB, Rogerson ME, Bewick M, Parsons V. Generalised epileptic fits in renal transplant recipients given cyclosporin A. Br Med J 1984; 289:1347-8.

7 Berden JHM, Hoitsma AJ, Merx JL, Keyser A. Severe central-nervous-system toxicity associated with cyclosporin. Lancet $1985 ; \mathbf{i}: 219-20$.

8 Griffith BP, Hardesty RL, Trento A, Lee A, Bahnson HT. Targeted blood levels of cyclosporine for cardiac transplantation. J Thorax Cardiovasc Surg 1984;88: 952-7.

9 Thompson CB, June CH, Sullivan KM, Thomas ED. Association between cyclosporin neurotoxicity and hypomagnesaemia. Lancet 1984;ii:1116-20.

10 Kunzendorf U, Brockmoller J, Jochimsen F, Keller F, Walz G, Offermann G. Cyclosporin metabolites and central nervous system toxicity. Lancet 1988;i:1223. 